\title{
Pledges for the new year
}

\author{
Elizabeth Loder head of research
}

The BMJ

It's the time for a fresh set of resolutions. If one of yours is to lose or maintain weight, you might be wondering if it makes sense to use non-sugar sweeteners instead of sugar. Ingrid Toews and colleagues (doi:10.1136/bmj.k4718) conducted a systematic review and meta-analysis of the effects of non-sugar sweeteners on various health outcomes, including weight. For adults, use of non-sugar sweeteners rather than sugar was associated with small improvements in body mass index and fasting blood glucose levels. There was no evidence of beneficial effects on other outcomes, including cancer, cardiovascular disease, mood, or cognition. In the linked editorial Vasanti Malik says that the preponderance of evidence indicates that replacing free sugar with non-sugar sweeteners, especially in beverages, "could be a helpful strategy to reduce cardiometabolic risk" (doi:10.1136/ bmj.k5005). The ultimate goal, however, is a switch to water or other drinks with health benefits.

Meanwhile, Melanie Newman suggests that some New Year's Day resolutions might be in order for Cochrane, the leading evidence based medicine group (doi:10.1136/bmj.k5302). Its sacking of the high profile founding member Peter Gøtzsche has unleashed a firestorm of criticism and condemnation. Cochrane is accused of straying from its core scientific mission to produce unbiased, high quality systematic reviews. Now, some say, it has become a corporate machine, churning out reviews of variable quality to maximise income from royalties. Cochrane's conflict of interest policies are also a source of disagreement, in particular whether individual centres can be funded by commercial sources and the extent to which employees of manufacturers are involved in reviews. The way forward, Newman finds, will involve a renewed commitment to communication and diplomacy, as well as a dose of humility. Another study this week concludes that healthcare institutions around the world should resolve to set and adhere to standards for radiation doses from computed tomography examinations (doi:10.1136/bmj.k4931). Exposure to radiation from diagnostic procedures is increasing and raises the risk of future cancers. ${ }^{1}$ Rebecca Smith-Bindman and colleagues examined data on radiation doses from over two million CT examinations of specific anatomical areas in seven countries. Even after they adjusted for patients' characteristics, they found wide variation in radiation doses within and between countries. For example, the proportion of abdominal CT scans that delivered doses above the 75th percentile ranged from a low of $4 \%$ to a high of $69 \%$. Because technical parameters rather than patient factors explained most of the differences in radiation exposure, the authors conclude there is an urgent need to optimise doses to a consistent standard.

\section{New BMJ policy on plans for dissemination of research findings}

As for The BMJ, our New Year's pledge is an extension of our commitment to open science and involvement of patients and the public in all stages of the research enterprise. "Research is of no use unless it gets to the people who need to use it," says Chris Whitty, chief scientific adviser for England's Department of Health. ${ }^{2}$ We agree, and as of 1 January we are asking authors of research papers to describe plans for dissemination of their findings to research participants and other relevant communities. We want to know how patients and the public were, or will be, involved in choosing the methods and developing plans to share research findings, and when and how dissemination has been or will be done.

1 Linet MS, Slovis TL, Miller DL, etal . Cancer risks associated with external radiation from diagnostic imaging procedures. CA Cancer J Clin 2012;62:75-100. 10.3322/caac.21132 22307864

National Institute for Health Research. How to disseminate your research. https://www. nihr.ac.uk/funding-and-support/documents/funding-for-research-studies/manage-mystudy/How-to-disseminate-your-research/dissemination-guidance.pdf.

Published by the BMJ Publishing Group Limited. For permission to use (where not already granted under a licence) please go to http://group.bmj.com/group/rights-licensing/ permissions 